\title{
Effects of Thickness on Optical and Structural Properties of Lead Sulphide (PbS) Thin Film Prepared by Chemical Bath Deposition (CBD)
}

\author{
Bayisa Batu Tolasa Tamasgen \\ Department of physics, Bonga University, Bonga, Ethiopia
}

\begin{abstract}
Nanocrystalline $\mathrm{PbS}$ thin films were deposited on glass substrates with various deposition times using chemical bath deposition technique. $\mathrm{PbS}$ thin films were prepared by using a solution of Lead nitrate and thiourea by using $\mathrm{NaOH}$ salt as a complexing agent and ammonia solution as a $\mathrm{pH}$ adjuster at $65^{\circ} \mathrm{C}$. The study was carried out for thickness in the range of $(0.16-1.03 \mathrm{~m})$. The structural properties were carried out by X-ray diffraction (XRD). The $\mathrm{X}$-ray diffraction patterns reveal that the films exhibit the cubic face centered structure. The crystalline sizes of the films increased with increasing film thickness. The morphological properties were studied by SEM and showed that films were well adherent to the substrate, uniform, small crystal size and covered the entire substrate surface completely. The optical properties of these films have been studied and show that $\mathrm{PbS}$ thin films have the values of energy gap varied between $(0.88-1.34 \mathrm{eV})$ with increasing film thickness.
\end{abstract}

Keywords: $\mathrm{CBD}, \mathrm{XRD}$, band gap, $\mathrm{PbS}$ thin film

DOI: $10.7176 / \mathrm{CMR} / 12-7-01$

Publication date:September $30^{\text {th }} 2020$

\section{Introduction}

Lead Sulphide $(\mathrm{PbS})$ is cluster IV-VI chalcogenides semiconductor that has direct optical band gap of $0 \cdot 41$ electron volt and has a cubic structure $[1,21]$. The colour of $\mathrm{PbS}$ is grayish-black. It's high absorbance within the UV-Vis spectral vary and high transmittance within the infrared spectral region of allowing its use in infrared detectors [2,9]. Thin film of lead sulphide is useful in the manufacture of transistors[3], photoconductive infra-red detectors[4], windows, contact rectifiers, prisons, lenses[5], photovoltaic application in solar cells[6], solar control coating[7], optoelectronic devices[8], antireflection coatings and for solar thermal applications[9] in flat-plat collectors, house heating for solar chick brooding (11), Photo resistance, diode lasers, humidity and temperature sensors, decorative coatings and solar control coatings [12], pollution monitor[25].

Many techniques have been reported for the deposition of thin films such as Chemical spray deposition (CSP) [26], Molecular beam epitaxy [13], chemical vapor deposition (CVD) [15], sol-gel spin coating [16], successive ion layer absorption and reaction (SILAR) method[4], chemical bath deposition (CBD) [13] ect. Among them chemical bath deposition (CBD) method does not require sophisticated instrumentation [17]. It is relatively cheap, convenient for large area deposition [11], simple to handle, and capable of yielding good quality thin films [17].

The film thickness being one of parameters, which affects the properties of the thin film. The film thickness can be measured by the gravimetric method [18], Tolansky method [12], interference fringes, ellipsometry method and weight difference method [18].

In this research Lead sulphide $(\mathrm{PbS})$ thin film were deposited at $65^{\circ} \mathrm{C}$ from lead nitrate $\left(\mathrm{Pb}\left(\mathrm{NO}_{3}\right)_{2}\right)$ thiourea $\left(\mathrm{SC}\left(\mathrm{NH}_{2}\right)_{2}\right)$, sodium hydroxide $(\mathrm{NaOH})$ and ammonium hydroxide $\left(\mathrm{NH}_{4} \mathrm{OH}\right)$ by using Chemical bath deposition method and it's thickness were measured by weight difference method

Lead Sulphide $(\mathrm{PbS})$ is cluster IV-VI chalcogenides semiconductor that has direct optical band gap of $0 \cdot 41$ electron volt and encompasses a cubic structure [1,21]. the color of $\mathrm{PbS}$ is grayish-black. It's high absorbance within the UV-Vis spectral vary and high transmittance within the infrared spectral region of allowing its use in infrared detectors [2,9]. Thin film of lead sulphide is helpful within the manufacture of transistors[3], photoconductive infra-red detectors[4], windows, contact rectifiers, prisons, lenses[5], photovoltaic application in solar cells[6], solar control coating[7], optoelectronic devices[8], antireflection coatings and for solar thermal applications [9] in flat-plat collectors, house heating for solar chick brooding (11), Photo resistance, diode lasers, humidity and temperature sensors, decorative coatings and solar control coatings [12], pollution monitor[25]. Many techniques are reported for the deposition of thin films like Chemical spray deposition (CSP) [26], Molecular beam epitaxy [13], chemical vapor deposition (CVD) [15], sol-gel spin coating [16], successive ion layer absorption and reaction (SILAR) method[4], chemical bath deposition (CBD) [13] ect. Among them chemical bath deposition (CBD) method doesn't require sophisticated instrumentation [17]. it's relatively cheap, convenient for big area deposition [11], simple to handle, and capable of yielding good quality thin films [17]. The film thickness being one amongst parameters, which affects the properties of the skinny film. The film thickness will be measured by the gravimetric method [18], Tolansky method [12], interference fringes, ellipsometry method and weight difference method [18]. In this research Lead sulphide $(\mathrm{PbS})$ thin film were deposited at 650C from lead nitrate 
$\left(\mathrm{Pb}\left(\mathrm{NO}_{3}\right)_{2}\right)$ thiourea $\left(\mathrm{SC}\left(\mathrm{NH}_{2}\right)_{2}\right)$, caustic soda $(\mathrm{NaOH})$ and ammonia $\left(\mathrm{NH}_{4} \mathrm{OH}\right)$ by using Chemical bath deposition method and it's thickness were measured by weight difference method

\section{Materials and Methods}

Lead sulphide thin films were deposited on substrate by the chemical bath deposition method. The precursor chemicals were lead nitrate $\left(\mathrm{Pb}\left(\mathrm{NO}_{3}\right)_{2}\right)$, thiourea $\left(\mathrm{SC}\left(\mathrm{NH}_{2}\right)_{2}\right)$, sodium hydroxide $(\mathrm{NaOH})$, ammonium hydroxide $\left(\mathrm{NH}_{4} \mathrm{OH}\right)$. Thiourea is used as our sulphide ion source and leads nitrate as our lead ion source. Ammonia is as $\mathrm{PH}$ adjuster, $\mathrm{NaOH}$ as complex agent. Lead sulphide were constituted from a solution of $5 \mathrm{ml}$ of $0.06 \mathrm{M}$ lead nitrate $\left(\mathrm{Pb}\left(\mathrm{NO}_{3}\right)_{2}\right), 5 \mathrm{ml}$ of $0.2 \mathrm{M}$ thiourea, $10 \mathrm{ml}$ of $0.25 \mathrm{M}$ sodium hydroxide, $7 \mathrm{ml}$ ammonia and distilled water of $43 \mathrm{ml}$ were added to the solution making it total of $70 \mathrm{ml}$. Cleaned substrates were vertically immersed into the solution and was maintained $65^{\circ} \mathrm{C}$ temperature. After the deposition, the slides were removed from the chemical bath at $17,22,27,32 \mathrm{~min}$ for four samples respectively. the thin film was rinsed with distilled water and dried in air. The resulting films were homogeneous, uniform and well adhered to the substrate with dark surface. A mirror-like surface was obtained. The thickness was measured by weight different method. In this case the mass of cleaned substrate was measured before deposition and after deposition. Then the difference between two mass was obtained by subtracting the mass of substrate before deposition from mass of substrate with thin film. From its general properties, the density of $\mathrm{PbS}$ is constant which is $7.60 \mathrm{~g} / \mathrm{cm}^{3}$. The length and width of deposited thin film were measured by ruler. Then the area of the film was calculated from width and length of the film. The Thickness was calculated by using the following formula [18].

$T=\frac{\Delta M}{\rho M}$

where A is area of the film, $\rho$ is density of the film, difference between two mass and $\mathrm{T}$ is thickness of the film. Four samples were measured according to the following table.

Table 1: Thickness of measured each film

\begin{tabular}{|l|l|l|l|l|l|}
\hline time $(\mathrm{min})$ & $\mathrm{A}(\mathrm{cm})^{2}$ & $\mathrm{~m} . \mathrm{B}$ deposition $(\mu \mathrm{g})$ & m.A deposition $(\mu \mathrm{g})$ & $\mathrm{M} . \mathrm{D}(\mu \mathrm{g})$ & thickness $(\mu \mathrm{M})$ \\
\hline 17 & 5 & 42708 & 42714 & 6 & 0.16 \\
\hline 22 & 5 & 42162 & 42181 & 19 & 0.5 \\
\hline 27 & 5 & 45623 & 45660 & 37 & 0.97 \\
\hline 32 & 5 & 44929 & 44968 & 39 & 1.03 \\
\hline
\end{tabular}

where t,m.B,m.A,m.D are time,mass before deposition,mass After deposition,mass difference re-

spectively

\section{Result and discussion}

Reaction mechanism

$$
\begin{aligned}
& \mathrm{Pb}\left(\mathrm{NO}_{3}\right)_{2}+2 \mathrm{NaOH} \rightarrow \mathrm{Pb}(\mathrm{OH})_{2}+2 \mathrm{NaNO}_{3} \\
& \mathrm{~Pb}(\mathrm{OH})_{2}+4 \mathrm{NaOH} \rightarrow \mathrm{Na}_{4} \mathrm{~Pb}(\mathrm{OH})_{6} \\
& \mathrm{Na}_{4} \mathrm{~Pb}\left(\mathrm{OH}_{6} \rightarrow 4 \mathrm{Na}^{+}+\mathrm{HPbO}^{2-}+3 \mathrm{OH}^{-}+\mathrm{H}_{2} \mathrm{O}\right. \\
& \mathrm{SC}\left(\mathrm{NH}_{2}\right)_{2}+\mathrm{OH}^{-} \rightarrow \mathrm{CH}_{2} \mathrm{~N}_{2}+\mathrm{H}_{2} \mathrm{O}+\mathrm{SH}^{-} \\
& \mathrm{HPbO}^{2-}+\mathrm{SH}^{-} \rightarrow \mathrm{PbS}+2 \mathrm{OH}^{-}
\end{aligned}
$$

\section{Optical characterization}

The optical energy gap (Eg) of PbS thin films were determined using Uv-3600. The optical absorption spectrum of $\mathrm{PbS}$ were calculated in wave length range of 700-1800. The optical band gap was calculated by using stern equation $[20,24]$.

$$
A=\frac{\left[K\left(h v-E_{g}\right]^{\frac{n}{2}}\right.}{h v}
$$

Where $v$ is the frequency of the incident photon, $h$ is Planck' $s$ constant $A$ is constants and $n$ is the number which characterizes the optical processes. The plots of the $(\mathrm{Ah} v)^{2}$ as a function of $\mathrm{h} v$ are shown in fig 1 . in accordance with equation 2. The film thickness dependence of band gap energy can be due to factors like the existence of amorphous phases in thin films, Quantum confinement effect $[6,19]$ and change in barrier height owing to change in grain size in polycrystalline films [6]. 
In this is case, it can be considered that the thickness dependence of band gap energy is concerned with the crystallinity of the films. The decrease in band gap energy with film thickness is similar to its crystallite size dependence, which indicates the decrease in barrier height at the boundaries with an increase in crystallite size. The value of energy was decrease as thickness of the film is increase. This may be due to increase in crystallite size, crystal imperfection and, decrease in stacking faults [22]. The larger crystallite size leads to an increase in absorption. As a result, the optical absorption edge shift towards longer wavelengths and consequently band gap decreases. As we see from fig. 1 . the value of band gap is $1.34,1.12,0.92,0.88 \mathrm{eV}$. for thickness $0.16,0.5,0.97,1.03$ $\mu \mathrm{m}$ respectively.

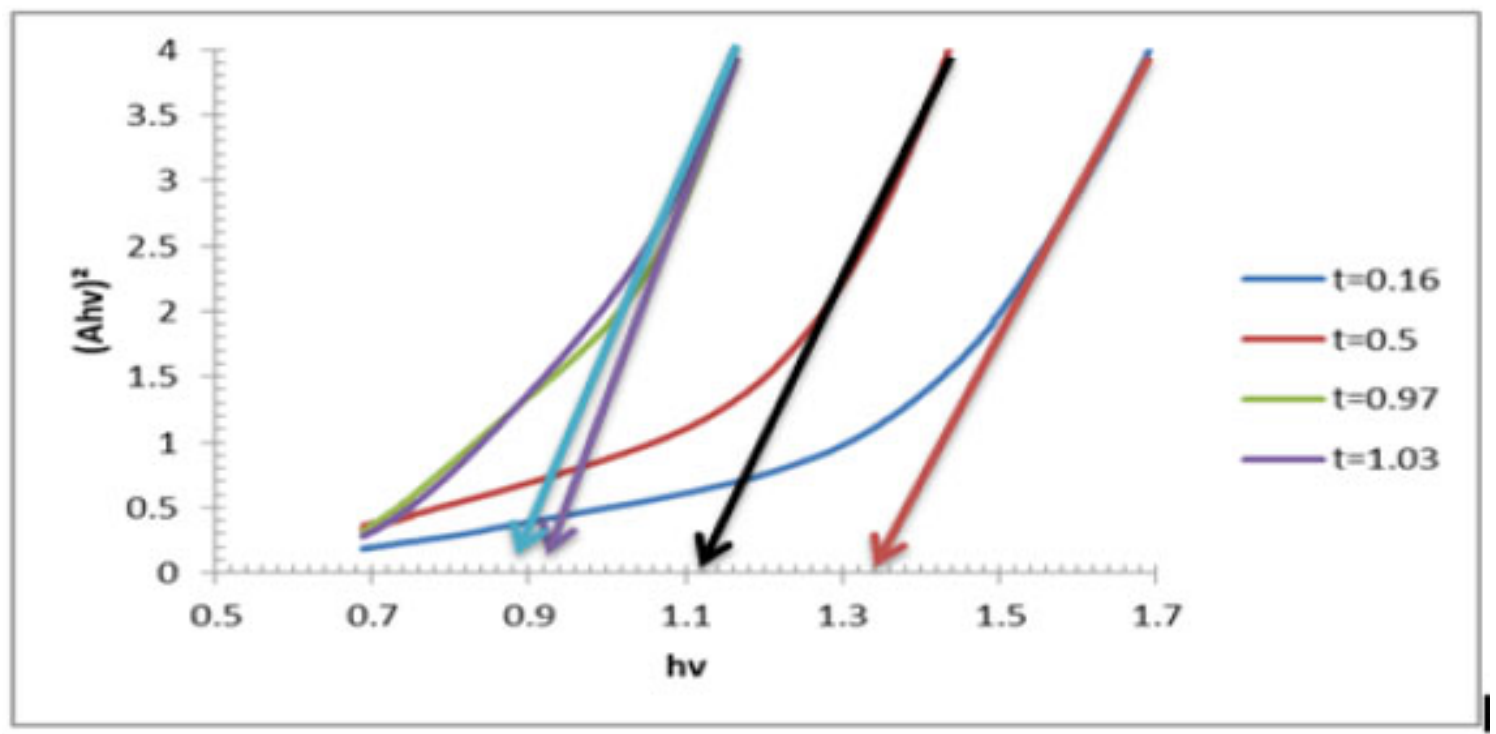

Fig1. plot of $(A h v)^{2}$ versus band gap for all samples

\section{Structural Characterization}

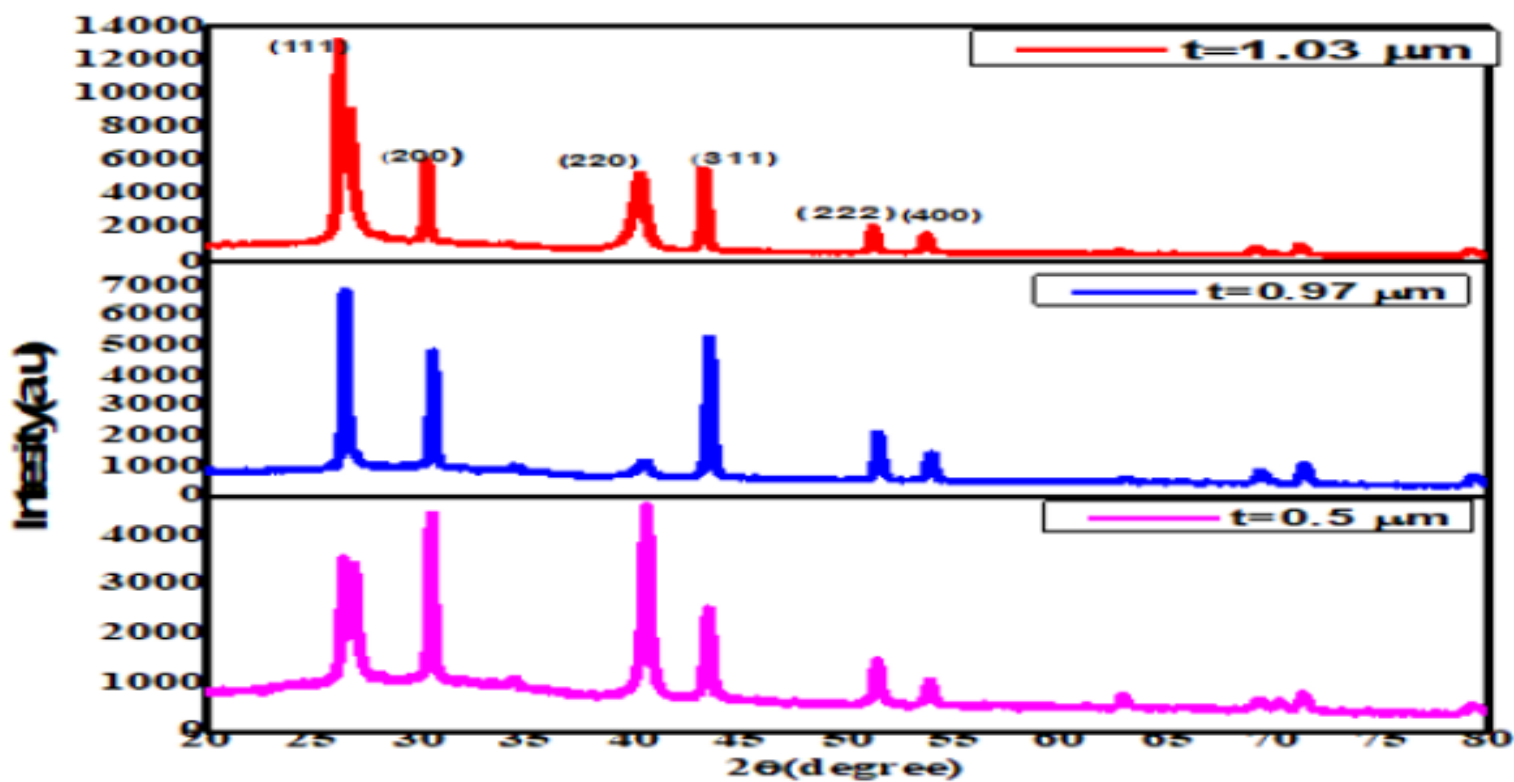

Figure 2. XRD characterization for all $0.5,0.97$ and $1.03 \mu \mathrm{m}$

From Fig.2. the X-ray diffraction of $\mathrm{PbS}$ thin films with thickness $0.5,0.97$ and $1.03 \mu \mathrm{m}$. For thickness $0.5 \mu \mathrm{m}$ the diffraction peaks at 26.450,30.540, 40.600, 43.480, 51.420 and 53.850 which, respectively, correspond to the (111), (200), (220),(311), (222) and (331), Miller planes of the PbS phase with cubic structure (galena), for thickness $0.97 \mu \mathrm{m}$ produced peaks at $26.50^{\circ}, 30.60^{\circ}, 43.56^{\circ}, 51.46^{\circ}, 53.91^{\circ}$ and $71.39^{\circ}$ corresponding to the Miller planes (111), (200), (220), (311),(222) and (400) respectively as well as the thickness $1.03 \mu \mathrm{m}$ produced peaks at $26.23^{\circ}, 30.34^{\circ}, 40.30^{\circ}, 43.32^{\circ}$ and $51.24^{\circ}$ corresponding to the Miller planes (111), (200), (220), (311),(222) and (400). The diffraction pattern was well matched with the standard JCPDS data file reference code: No.00-005- 
0592 of the face centered cubic structure. The intensity of the peaks in $1.03 \mu \mathrm{m}$ films is higher than those of the 0.5 and $0.97 \mu \mathrm{m}$ films because the thickness of the films of $1.03 \mu \mathrm{m}$ was larger than others films. The preferred growth orientation in films changed from (220) to (111) with increasing thickness. This due to formation of Nano crystalline film. The presence of well-defined and sharp peaks in all the XRD patterns is attributed to a high degree of crystallinity in the thin films. The crystallite size can be estimated by Debye-Scherer's equation using the line broadening of the highest intensity peak (220).

$D=\frac{0.94 \lambda}{\beta \cos \theta}$

Table 2: plot of crystalline size versus thickness of PbS Thin film

\begin{tabular}{|l|l|l|l|l|l|l|l|}
\hline $2 \theta(\mathrm{deg})$ & Thickness $(\mu \mathrm{m})$ & Time $(\mathrm{min})$ & hkl & FWHM(rad) & $\mathrm{D}(\mathrm{nm})$ & $(\epsilon)$ lines $^{-2} \mathrm{~m}^{-4}$ & $(\delta)\left(\hat{I}^{\prime}\right) l$ lines $/ \mathrm{m}^{2}$ \\
\hline 40.6019 & 0.5 & 22 & 220 & 0.41396 & 0.06 & $3.65 \times 10^{-3}$ & $0.278 \times 10^{15}$ \\
\hline 26.5089 & 0.97 & 27 & 111 & 0.19787 & 0.126 & $2.75 \times 10^{-3}$ & $0.063 \times 10^{15}$ \\
\hline 26.23251 & 1.03 & 32 & 111 & 0.18692 & 0.133 & $2.60 \times 10^{-3}$ & $0.057 \times 10^{15}$ \\
\hline
\end{tabular}

Where, $\lambda$ is the $\mathrm{X}$-ray wavelength $\left(1.5406 \mathrm{~A}^{\circ}\right),(\beta)$ is the line broadening of diffraction at half of its maximum intensity, $\mathrm{k}$ is the constant numerator value (0.94). the lattice parameters for cubic phase(hkl) calculated as follows. The strain and dislocation density $(\delta)$ were evaluated by using Williamson and tangent relations, respectively $E=\frac{\beta \cos \theta}{4}$ $\delta=\frac{1}{D^{2}}$

The obtained dislocation density and macrostrain values were low, which indicates the presence of minimum defects in the prepared films. The strain decreased with increasing film thickness indicating that the improvement of the stoichiometric ratio of $\mathrm{PbS}$ thin films with increasing film thickness. The dislocation density also decreased with increasing crystallite size. It may be due to a decrease in the occurrence of grain boundaries because of an increase in the crystallite size of the film with increasing film [23]. FWHM of the peaks decreased with increase in thicknesses of $\mathrm{PbS}$ thin films, thus confirming inverse relation between dislocation density and crystallinity and hence it is concluded that increase in thickness improved crystallinity. As the thickness increased, the crystallite size changed, so dislocation density and strain decreases. The lattice constant, $a_{h k l}$ for $\mathrm{PbS}$ thin films with the cubic face centered structure was calculated using Bragg diffraction equations:

$a_{h k l}=d_{h k l} \sqrt{h^{2}+k^{2}+l^{2}}$

Where $d_{h k l}$ represents the distance between the (hkl) atomic lattice planes. The lattice constant of the PbS thin films varies as $6.2 \mathrm{~A}^{\circ}, 4.5 \mathrm{~A}^{\circ}$ and $2.5 \mathrm{~A}^{\circ}$ with increasing thickness. where $\delta$ is dislocation density, $\varepsilon$ is strain size.

\section{Morphological Characterization}

The morphology of $\mathrm{PbS}$ thin films of thickness $0.97 \mu \mathrm{m}$ deposited on substrate was examined by scanning electron microscopy (SEM) (Fig.3). The surface of the film is uniform and covers the entire substrate without cracks and holes. And also, it reveals that the film formed is smooth and dense. the grains in the film are relatively good, compact, homogeneous and uniformly covered at thickness $0.97 \mu \mathrm{m}$. 

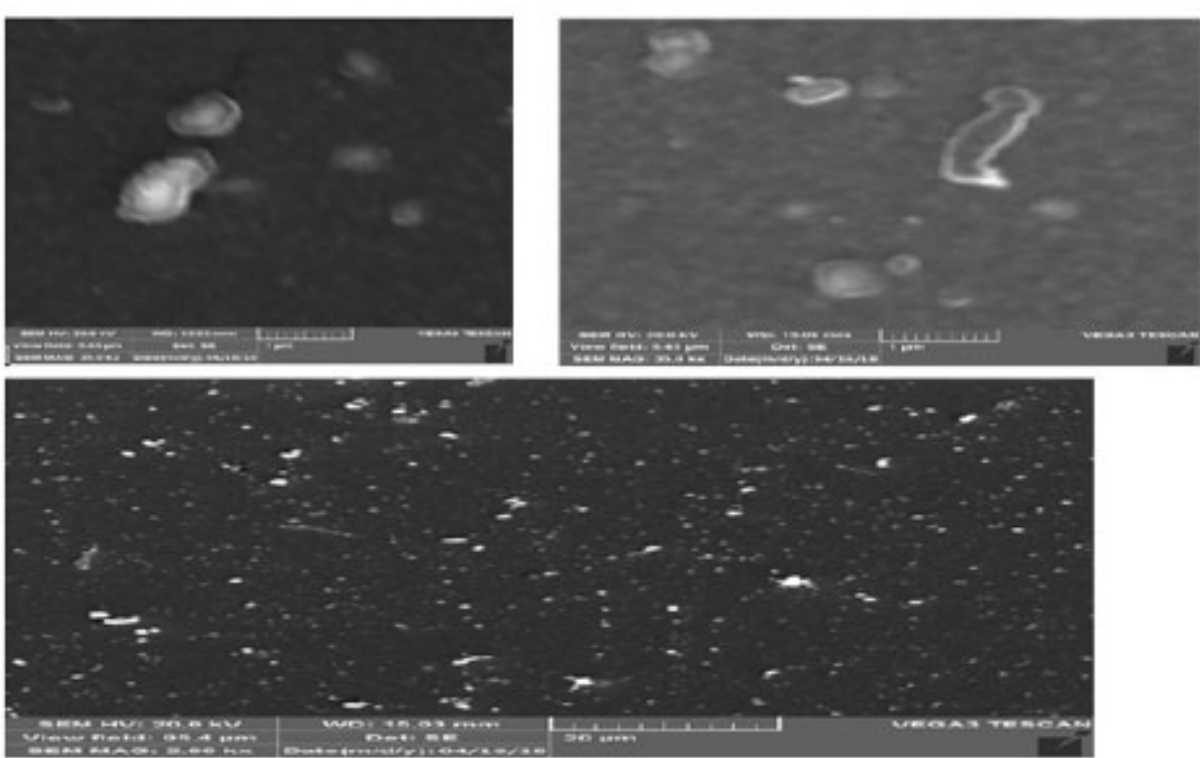

Figure 3: SEM Characterization for thickness $0.97 \mu \mathrm{m}$

\section{Elemental Characterization}

The a) and b) show distribution $\mathrm{Pb}$ and $\mathrm{S}$ respectively. Figure c) shows the EDX analysis of $\mathrm{PbS}$ thin Film indicate the presence lead and Sulphur. The calculated $\mathrm{Pb} / \mathrm{S}$ atomic ratio of thin film deposited at thickness $0.97 \mu \mathrm{m}$ was 0.53:0.47 which show the lead was reach than sulphide. The average atomic percentage of $\mathrm{S}$ to $\mathrm{Pb}$ was 1.13. which showed that the sample was non stoichiometric. but the strong peak is from silicon. This is may be due to the formation of very thin film. Other elements such as Carbon, Oxygen, $\mathrm{Ca}$, and $\mathrm{Si}$ are observed. Those are may due to the composition of the silica glass substrate. (The oxygen content found in the EDX spectrum could either emanate from the substrate or due to the films getting oxidized on exposure to the atmosphere).
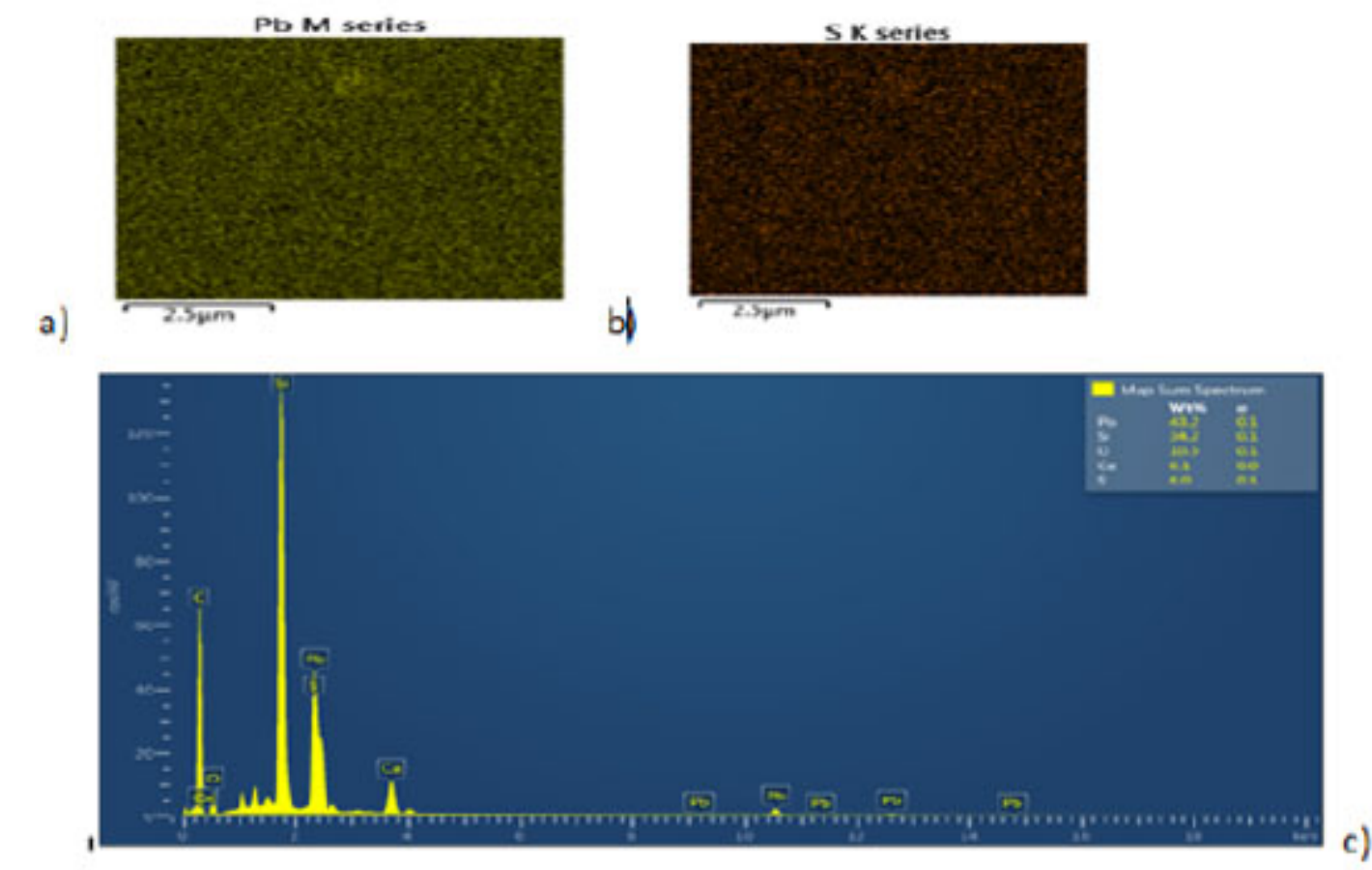

Figure 4: EDS analysis for thickness $0.97 \mu \mathrm{m}$

\section{Conclusion}

In this studies $\mathrm{PbS}$ thin films at $65^{\circ} \mathrm{C}$ temperature were prepared by a simple chemical Bath Deposition method. The thickness of the films varied from $0.16 \mu \mathrm{mto} 1.03 \mu \mathrm{m}$. The Effects of thickness on the structural and optical 
properties of the films were studied. The characteristics of $\mathrm{PbS}$ thin films were investigated by various tools. The $\mathrm{X}$-ray diffraction patterns confirm the proper phase formation of the $\mathrm{PbS}$ thin film. For the first sample, the preferential orientation value of (220) plane has the highest value compared to other planes and for second and third samples the preferential orientation to change to (111). The crystalline size of the PbS films increased with increasing film thickness. The values of crystallite size were found to be in the range of $0.6-1.3 \mathrm{~nm}$. The SEM study show that the film is well adherent to the substrate, uniform and covers entire substrate. The results of XRD and SEM show that the deposited PbS film consists of nano-sized crystalline and the crystalline size increases with increasing film thickness. The optical band gap energy varies from 0.86 to $1.34 \mathrm{eV}$ with increasing thickness.

\section{References}

[1]. N. Choudhury and B. K. Sarm, Structural characterization of lead sulfide thin films by means of X-ray line profile analysis, Bull Mater. Sci., 32(2009) 43-47

[2]. Ezenwa I.A. Effect of Film Thickness on the Transmittivity of Chemical Bath Synthesized PbS Thin Film, Research Journal of Engineering Sciences.2(2013)23-25

[3]. Putley EH Materials used in Semiconductor Devices, 2nd Ed., John Wiley and sons Ltd. N.Y, 1967

[4]. Homraruen, T. Sudswasd, Y. Sorod, R. Kayunkid, N. Yindeesuk, W, study of structural and optical properties of $\mathrm{PbS}$ thin films, Nata Astrophysics system, 2018-03-01

[5]. Ballard S.S, Browder JS, Ebersole JF (1972). American Institute of Physics Handbook, 3rd ed., D.E Gray McGraw-Hill Book Co. N.Y. p.59

[6]. E. Veena, Kasturi V. Bangera, G.K. Shivakuma, Effective role of thickness on structural, electrical and optical properties of lead sulphide thin films for photovoltaic applications, Materials Science and Engineering B 223 (2017) 64-69

[7]. K.C. Preetha, K. Deepa, A.C. Dhanya and T.L. Remadevi, Role of complexing agents on chemical bath deposited PbS thin film characterization, Materials Science and Engineering 73 (2015) 012086

[8]. F. Göde, F. Yavuz and I.A. Kar iper, Preparation and Characterization of Nanocrystalline PbS Thin Films Produced by Chemical Bath Deposition, Special issue of the International Conference on Computational and Experimental Science and Engineering Vol. 128 (2015)

[9]. B. A. Ezekoye, T. M. Emea karoha, V. A. Ezekoye, K. O. Ighodalo and P. O. Offor, Optical and structural properties of lead sulphide $(\mathrm{PbS})$ thin films synthesized by chemical Bath Deposition method, International Journal of Physical Science, 10(2015)385-390

[10]. Osherov, A., makai, J., Balasz, J., Horvath, Z., Gutman, N., Amir, S. and Golan, Y. Tenability of optical band edge in thin PbS films chemically deposited on GaAs(100). Journal of Condensed Matter, 22(2010)1-7

[11]. M. M. Abbas, A. Ab-M. Shehab, A-K. Al-Samuraee, and N-A. Hassan, Effect of Deposition Time on the Optical Characteristics of Chemically Deposited Nanostructure PbS Thin Films, Energy Procedia 6 (2011) 241-250

[12]. Angel Susan Cherian, J. V. emil, M. C. Thomson, C. V. Rashida and S. Malus, PbS Thin Films Using Cost Effective Chemical Method and Enhancement in its Conductance, Physical Science, 2015, A2, 00-00

[13]. A Hussain, A Begum and A Rahman, Electrical and optical properties of nanocrystalline lead sulphide thin films prepared by chemical bath deposition, Indian J Phys (2012) 86(8):697-701

[14]. A.R. Mandal, A. Bekturganova, A. Ishteev, S.P. Choudhury, G. Karunakaran, D. Kuznetsova, Effect of silver doping on the current-voltage characteristic of PbS nanorods, Physica E 79 (2016) 147-151

[15]. M.D. Khan, S. Hameed, N. Haider, A. Afzal, S. Sportelli, N. Cioffi, M.A. Malik, J. Akthar, Deposition of morphology tailored $\mathrm{PbS}$ thin films by surfactant enhanced aerosol assisted chemical vapor deposition, Mater. Sci. Semicond. Process. 46 (2016) 39-45.

[16]. Jeevitesh K. Rajputa, Trilok K. Pathaka,b, V. Kumara,b, H.C. Swartb and L. P. Purohit, Tailoring and Optimization of Optical Properties of CdO Thin Films for gas sensing Applications, Physica B: 535 (2018) 314-318

[17]. Milton Ohring, Materials Science of Thin Films Deposition and Structure, Second Edition, Department of Materials Science and Engineering,Stevens Institute of Technology,Hoboken

[18]. Ph. D. Thesis submitted by Mr. Jagannath Babu Chaudhari growth and study of optical and electrical properties of chemically deposited cds1-xsex:ag nanocomposite thin films for sensor application

[19]. Deuk Ho Yeon, Seung Min Lee, Yeon Hwa Jo, Jooho Moon and Yong Soo Cho, Origin of the enhanced photovoltaic characteristics of $\mathrm{PbS}$ thin film solar cells processed at near room temperature, J. Mater. Chem. A, 2014, 2,20112

[20]. Kassim, A., Tan, W.T., Haron, Md.J., Min, H.S., Gwee, S.Y. and Nagalingam, S. (2010) Effects of Deposition Period on the Properties of FeS2 Thin Films by Chemical Bath Deposition Method. Thammasat International Journal of Science and Technology, 15, 62-69.

[21]. S. Seghaier, N. Kamoun, R. Brini, A.B. Amara, Structural and optical properties of PbS thin films deposited by chemical bath deposition, Materials Chemistry and Physics 97 (2006) 71-80 
[22]. N. Kavitha, R. Chandramohan, S. Valanarasu, T. A. Vijayan, S. Rex Rosario, A. Kathalinga Effect of film thickness on the solar cell performance of CBD grown CdS/PbS heterostructure, J Mater Sci: Mater Electron, 12 August 2015 / Accepted: 8 November 2015

[23]. Fekadu Gashaw Hone, Francis Kofi Ampong, Tizazu Abza, Isaac Nkruma, Mark Paal, Robert Kwame Nkum,Francis Boakye, The effect of deposition time on the structural, morphological and optical band gap of lead selenide thin films synthesized by chemical bath deposition method, Materials Letters

[24]. Ho Soon Min, Influence of deposition time on optical properties of chemically deposited nickel lead sulphide thin films, International Journal of Applied Chemistry.1 (2017)111-120

[25]. Siham Mahmoud and Omar Hamid, "Growth and Characterization of Lead-Sulfide Films Deposited on Glass Substrates", 307 , (2001), 240.

[26]. Mohammad Ghaffar Faraj, Effect of Thickness on the Structural and Electrical Properties of Spray Pyrolysed Lead Sulfide Thin Films, American Journal of Condensed Matter Physics 2015, 5(2): 51-55 